\begin{tabular}{|c|c|c|c|}
\hline $\begin{array}{l}\text { Submission: } 19 / \mathrm{Feb} / 2021 \text {; } \\
\text { Camera ready: } 15 / \mathrm{Jul} / 2021 \text {; }\end{array}$ & $\begin{array}{l}1^{\text {st }} \text { round notif.: } 05 / \mathrm{May} / 2021 \text {; } \\
\text { Edition review: } 22 / \mathrm{Jul} / 2021 \text {; }\end{array}$ & $\begin{array}{l}\text { New version: } 24 / \mathrm{May} / 2021 \text {; } \\
\text { Available online: } 06 / \mathrm{Aug} / 2021 \text {; }\end{array}$ & $\begin{array}{l}2^{\text {nd }} \text { round notif.: } 30 / \mathrm{Jun} / 2021 \text {; } \\
\text { Published: 06/Aug/2021; }\end{array}$ \\
\hline
\end{tabular}

\title{
Recomendações de Acessibilidade para Recursos Educacionais Abertos com Foco em Pessoas com Deficiência Visual
}

\author{
Title: Accessibility Recommendations for Open Educational Resources Focusing on Visually \\ Impaired People
}

Welber Duarte dos Santos

Universidade de São Paulo - ICMC

welber_duarte@hotmail.com

\author{
Camila Dias de Oliveira Sestito \\ Universidade de São Paulo - ICMC \\ camila_oliveira@usp.br
}

\author{
Ellen Francine Barbosa \\ Universidade de São Paulo - ICMC \\ francine@icmc.usp.br
}

\begin{abstract}
Resumo
Recursos Educacionais Abertos (REAs), embora bastante populares, ainda não são acessíveis a todos os públicos. Apesar da grande quantidade de atividades e recursos gratuitos, as pessoas com deficiência visual ainda têm dificuldades em utilizar esses materiais no dia a dia. Assim, o objetivo dessa pesquisa é apresentar uma série de recomendações que auxiliem no desenvolvimento ou adaptação de REAs para a realidade desse público, facilitando o uso e conscientizando os profissionais da educação acerca da existência desse tipo de material. Foram analisados, portanto, a literatura, ferramentas, forma de utilização e dificuldades no cotidiano com os REAs, para elaborar um conjunto de recomendações de acessibilidade para pessoas com deficiência visual, com atenção ao tato, olfato, audição e alternativas digitais. As recomendações foram avaliadas de diferentes formas por: (i) um conjunto de especialistas das áreas de computação e educação; (ii) uma pessoa com deficiência visual, especialista em produção de materiais acessíveis; e (iii) um indivíduo cego, estudante dos anos finais do ensino fundamental. As análises possibilitaram a construção de recomendações atualizadas e detalhadas, que consideram diferentes contextos, domínios e artefatos. Os resultados mostraram que as recomendações podem auxiliar no processo de desenvolvimento de REAs mais acessíveis, sejam esses recursos físicos ou computacionais. Além disso, as recomendações sugerem materiais acessíveis à realidade das escolas brasileiras podendo, portanto, serem aplicados em diversos contextos, com intercâmbio de materiais e formas de aplicação, com escrita clara e objetiva.
\end{abstract}

Palavras-Chave: Tecnologias da Informação e Comunicação; Materiais adaptados; Inclusão escolar.

\begin{abstract}
Open Educational Resources (OERs), although quite popular, are not yet accessible to all audiences. Despite a large number of free activities and resources, people with visual impairments still have difficulties in using these materials daily. Thus, the goal of this research is to present a series of recommendations that assist in the development or adaptation of OERs to the reality of this audience, facilitating their use and raising awareness among education professionals about the existence of this type of material. Therefore, the literature, tools, form of use and daily difficulties with OERs were analyzed to elaborate a set of accessibility recommendations for people with visual impairment, with attention to touch, smell, hearing, and digital alternatives. The recommendations were evaluated in different ways by (i) a group of experts from the fields of computing and education; (ii) a person with visual impairment, a specialist in the production of accessible materials; (iii) a blind individual, a student in the final years of elementary school. The analyzes enabled the construction of updated and detailed recommendations, which consider different contexts, domains, and artifacts. The results showed that the recommendations can help in the process of developing more accessible OERs, whether these resources are physical or computational. In addition, the recommendations suggest materials that are accessible to the reality of Brazilian schools and, therefore, can be applied in different contexts, with the exchange of materials and forms of application, with clear and objective writing. Keywords: Information and Communication Technologies; Adapted Materials; School inclusion.
\end{abstract}

Cite as: Santos, W. D., Sestito, C. D. O., \& Barbosa, E. F. (2021). Recomendações de Acessibilidade para Recursos Educacionais Abertos com Foco em Pessoas com Deficiência Visual. Revista Brasileira de Informática na Educação, 29, 957-979. DOI: 10.5753/RBIE.2021.29.0.957 


\section{Introdução}

Por definição, Recursos Educacionais Abertos (REAs) são instrumentos de acesso aberto, adaptáveis, que são disponibilizados por meio de Tecnologias da Informação e Comunicação (TICs) a uma comunidade diversa sem objetivo comercial (UNESCO, 2002). São, portanto, artefatos produzidos por diferentes profissionais, de diversas regiões, compartilhados em repositórios distintos, que apoiam o usuário que deseja usar, reutilizar, remixar e compartilhar materiais que previamente foram produzidos para outros contextos. Envolvem vídeos, apostilas, livros, jogos, softwares e outros artefatos, usados em cursos abertos ou não, numa diversidade que a torna o projeto envolvendo os REAs importante em lugares distantes, para aplicações específicas (NETO e GARCIA, 2013).

Apesar da popularidade que vem ganhando nos últimos tempos, os REAs não têm origem recente. Surgem no mundo digital vinculados ao ideal de educação aberta e aos Massive Open Online Course (MOOC ${ }^{1}$ ) (ALEVIZOU, 2015).

A primeira discussão sobre o termo REAs ocorreu em 2002, durante o fórum da UNESCO sobre cursos abertos para o ensino superior em países em desenvolvimento. Na ocasião, os participantes organizaram um evento com colaboração de diversas faculdades e universidades com objetivo de entender como utilizar de forma criativa e produtiva os recursos disponíveis (UNESCO, 2002).

No Brasil, a divulgação desses recursos partiu, principalmente, por iniciativa da Universidade Aberta do Brasil (UAB), com intuito de produzir conteúdo que atendesse aos cursos superiores de educação a distância. Assim, o compartilhamento em massa dos recursos fortaleceu o ideal de educação aberta criando uma cultura de criação, uso e reuso, alinhados com objetivos e práticas contemporâneas de educação aberta (SANTOS, 2013). Posteriormente, com a Declaração da Cidade do Cabo, em 2007, o Congresso Mundial sobre Recursos Educacionais Abertos, em 2012, o $10^{\circ}$ Aniversário da Declaração da Cidade do Cabo, em 2017, o Encontro para discutir REAs no Mercosul/América Latina, em 2018 e o mais recente marco, as Recomendações para REAs, de 2019, tomaram um caminho próprio, com incentivos governamentais e privados, passando a ser divulgados em plataformas distintas.

Por serem abertos para divulgação e personalização de acordo com os interesses do usuário, com atenção à licença, os REAs são uma interessante alternativa para trabalhar conteúdos sob determinadas particularidades, que necessitam de modificações pontuais (LEITE et al., 2018). A UNESCO (2019), em especial, recomenda que as estratégias e programas que incentivem o uso dos REAs tenham como princípio a acessibilidade, inclusão e igualdade. Nesse sentido, esses artefatos, produzidos da forma correta e recebendo tratamento específico para uso com leitores de tela e audiodescrição, por exemplo, podem se tornar item indispensável na vida dos estudantes com deficiência visual.

Apesar das iniciativas para educação com atenção específica para esses estudantes, pessoas com deficiência visual ainda lutam pelo seu direito à cidadania e acesso adequado aos serviços, para transpassar as desvantagens sociais históricas da sua comunidade (FRANCO e DIAS, 2007). As dificuldades saem do mundo físico e entram no digital, sendo necessário, assim, além dos mecanismos disponíveis, conjuntos de diretrizes como a Web Content Accessibility Guidelines (WCAG), que buscam "fornecer um único padrão compartilhado para acessibilidade de conteúdo da Web que atenda às necessidades de indivíduos, organizações e governos internacionalmente" (WCAG, 2018).

\footnotetext{
1 "São cursos online abertos, geralmente desenvolvidos por instituições acadêmicas, acessíveis a qualquer pessoa com acesso à internet” (UFRGS, 2018).
} 
Desta forma, o presente trabalho tem como principal objetivo apresentar um conjunto de recomendações que auxiliem na adaptação e/ou no desenvolvimento de REAs mais acessíveis para pessoas com deficiência visual, sejam esses recursos do meio físico ou digital. Com base em um levantamento bibliográfico, propõe-se um conjunto de 21 recomendações relacionadas ao tato, audição e olfato. O paladar foi excluído por questões que envolvem a saúde dos alunos e aplicadores das atividades. Além disso, a fim de complementar o trabalho e abordar mais especificamente questões computacionais, 15 recomendações digitais foram incluídas, levando em consideração as diretrizes de acessibilidade da WCAG 2.1 e materiais didáticos do Instituto Benjamin Constant (IBC).

\section{Recursos Educacionais Abertos e Acessibilidade}

REAs referem-se a quaisquer artefatos de ensino-aprendizagem e pesquisa que estejam em domínio público ou licenciados de maneira que permita seu uso e adaptação por qualquer pessoa (UNESCO, 2002). Podem ser recursos de aprendizagem, para apoio à aprendizagem; recursos de auxílio, para ajuda ao professor; ou recursos para garantia de qualidade, que examinem as características e boas práticas na educação (HYLÉN, 2005). De fato, REAs são artefatos que têm importante papel na cobrança de responsabilidade, investimentos e incentivos público/privados em TICs e infraestrutura de rede, possibilitando acesso também por comunidades distantes geograficamente, de baixa renda e urbanas (UNESCO, 2019).

Desde seu surgimento oficial, no fórum da UNESCO, em 2002, os REAs vêm ganhando espaço e se situando como uma importante ferramenta para educação aberta. Outros movimentos como o dos softwares livres, com sistemas como o Linux, por exemplo, sustentados sobre o pilar de levar serviço gratuito, otimizar o tempo gasto e possibilitar a colaboração em massa, ganham força e se estabelecem no século XXI para mudanças significativas nas TICs e como se relacionam com outros setores (DUTRA e TAROUCO, 2007).

Apesar da divulgação ter se acentuado a partir dos movimentos iniciados em 2002, a ideia de materiais abertos vem sendo discutida anos antes por acadêmicos de Harvard e do Massachusetts Institute of Technology (MIT). Willey, em 1998, impulsionado pelo movimento dos softwares livres, discutia sobre conteúdos abertos e dava alguns passos para a criação de uma licença para artefatos desse tipo. De forma semelhante, alguns alunos de Harvard, em 2001, viriam a criar o que hoje é conhecido como Creative Commons, fornecendo licenças para as tecnologias emergentes. No mesmo ano, o MIT disponibilizava seus cursos de maneira aberta para fins acadêmicos, consagrando e dando visibilidade ao movimento de abertura e liberdade aos artefatos diversos (DUTRA \& TAROUCO, 2007).

Com o crescimento e popularização apoiada em importantes instituições e incentivos governamentais, os REAs passaram a ser utilizados em situações que antes necessitavam de pesquisas e investimentos específicos, o que, em alguns casos, tornava-se demorado e complexo de ser explorado. Por meio da adaptação e desenvolvimento de conteúdo focado, os REAs fortalecem o rompimento de padrões preestabelecidos e garantem utilização de forma criativa de materiais que foquem em outros sentidos alheios à visão (ADAM e CALOMENO, 2013). Assim, o profissional envolvido com a educação da pessoa cega ou com visão subnormal têm um acervo de artefatos para utilização a favor do aluno de forma mais direta e livre de burocracias.

Apesar das novas possibilidades, a escola ainda está pouco acostumada a seu uso e acaba não aproveitando todos os meios para educar os alunos, bem como os interpreta de maneira equivocada. Conforme Mantoan (2003), os sistemas escolares ainda estão ligados a uma ideia de separação disso e daquilo, quando a sociedade deveria se preocupar em não definir lugares ou apenas colocar os indivíduos juntos, mas sim prover formas para que cada um possa se desenvolver. 
Dessa forma, levando em consideração a definição de acessibilidade web de Rocha e Duarte (2012), que a define como o que possibilita a interação de maneira a superar limitações e particularidades, e UNESCO (2019), que define Recomendações para REAs, no intuito de garantir o progresso ao ideal de educação aberta, os REAs devem ser considerados para mudar a realidade da educação, possibilitando a acessibilidade, inclusão e acesso dos mais diversos locais, em distintas formas, por pessoas de diferentes áreas e objetivos.

\subsection{Trabalhos relacionados}

Leite et. al (2018), na criação de REAs voltados à acessibilidade, desenvolveram uma disciplina de extensão que buscou trabalhar com REAs na inclusão digital. Durante a experiência, foram produzidos materiais abertos de orientação voltados à utilização de aplicativos e sites para públicos formados por idosos e crianças com altas habilidades.

Ainda no âmbito da inclusão digital, há o DOSVOX. Produzido no Núcleo de Computação Eletrônica da Universidade Federal do Rio de Janeiro, o software viabiliza e garante ao usuário cego ou com baixa visão independência no estudo e no trabalho (NCE/UFRJ, 2002, p. sem página). $\mathrm{O}$ projeto é construído com base o fortalecimento da acessibilidade, com cuidado ao tamanho da fonte e design das letras, audiodescrição, fundos pretos para melhor visualização, conversação em voz natural, importante na interação prolongada com o computador e outros diversos aspectos de sistemas específicos.

Outro importante ponto é a acessibilidade nos portais de REAs. Alguns deles, como é o caso do Livre Saber (LiSa), da Universidade Federal de São Carlos (UFSCar), preocupam-se com a organização do site para facilitar a navegação e utilização dos recursos por pessoas com deficiência. Para isso, o repositório aplica conceitos de HTML5, audiodescrição em elementos de vídeo e ilustrações e tradução em LIBRAS. Essas técnicas, apontadas anteriormente como alternativas importantes, somadas a diretrizes de construção do site como, por exemplo, o WCAG, possibilitam a inclusão digital, tão importante para viabilizar a acessibilidade (OTSUKA et al., 2015).

Além dos recursos digitais, alguns sentidos podem ser trabalhados com o aluno com deficiência visual, em busca de promover maior acessibilidade ao conteúdo e acesso à informação. Nesse caso, o tato pode ser um sentido a se considerar para adaptação de letras, números, espaços e até conceitos físicos, conforme mostram Adam e Calomeno (2013) (Figura 12). Nessa perspectiva, Preto (2009) cita algumas atividades que podem ser desenvolvidas com crianças com deficiência visual e materiais táteis, tais como: exploração de objetos quanto à sua textura, tamanho e peso, experiência com objetos/ambiente do cotidiano, experimentação dos símbolos em braille.

De forma semelhante, a audição é o principal sentido sensorial de um indivíduo a longa distância e, para o público com deficiência visual, é o único meio de perceber distância e profundidade para interagir com o ambiente (NUNES et. al, 2010). Nesse sentido, uma das tecnologias que ganhou popularidade nos últimos anos e que utiliza o sentido mencionado é o podcast, podendo ressaltar projetos como Rádio Legal e PodEscola (Barros e Menta, 2007; Freire, 2011). Para produção de materiais deste tipo, algumas estratégias podem ser consideradas: (1) o registro das vivências dos alunos; (2) elaboração de um programa do tipo rádio; (3) criação de uma biblioteca digital de textos gravados em áudio; (4) criação de um fórum/debate entre os alunos e professores sobre atividades; (5) gravação de entrevistas com pessoas envolvidas com o cotidiano da escola/disciplina; (6) interação dos alunos por meio de podcasts de turmas diferentes, formando um intercâmbio entre os alunos (JUNIOR e COUTINHO, 2009).

Outra possibilidade sobre a audição, diz respeito às adaptações que trabalham a localização espacial por meio dos sons, valorizando ao máximo a sonorização dos objetos em deslocamento para identificação de posição. Na prática, possibilita-se uma melhor orientação para a pessoa com 
deficiência visual durante uma atividade (Costa e Van Munster, 2017). As bolas guizo, por exemplo, são ótimos objetos voltados à educação física/esportes que aplicam o conceito na prática.

Assim como o tato e a audição, o olfato é um dos sentidos utilizados na educação de pessoas com deficiência visual. O trabalho de Nunes et al. (2010) descreve uma atividade utilizando o olfato como matriz. A pesquisa destaca que o indivíduo com deficiência visual constantemente precisa se orientar nos espaços de acordo com sua memória sensorial e o aroma pode ser marcante na construção espacial interna para localização do indivíduo em determinados ambientes. Esse ponto também é destacado no trabalho de Arruda (2016, p. 212), que desenvolveu maquetes multissensoriais.

Analisando os trabalhos científicos da área é possível notar que existe, atualmente, uma quantidade considerável de conceitos e práticas voltados à criação de atividades, em um contexto geral, voltados às pessoas com deficiência visual. A literatura, porém, não é tão abrangente quando o assunto é especificamente a produção de REAs acessíveis, possibilitando, portanto, poucos exemplos de adaptação com esse foco.

Diante disso, este estudo busca incentivar a proposição e construção de atividades, instruções e/ou ferramentas de REAs por meio de recomendações de acessibilidade para pessoas com deficiência. A Figura 1 expõe, com base em Mazzardo et al. (2019), uma linha do tempo sobre a criação dos REAs e onde as recomendações propostas podem ser utilizadas, evidenciando o caráter particular da pesquisa.

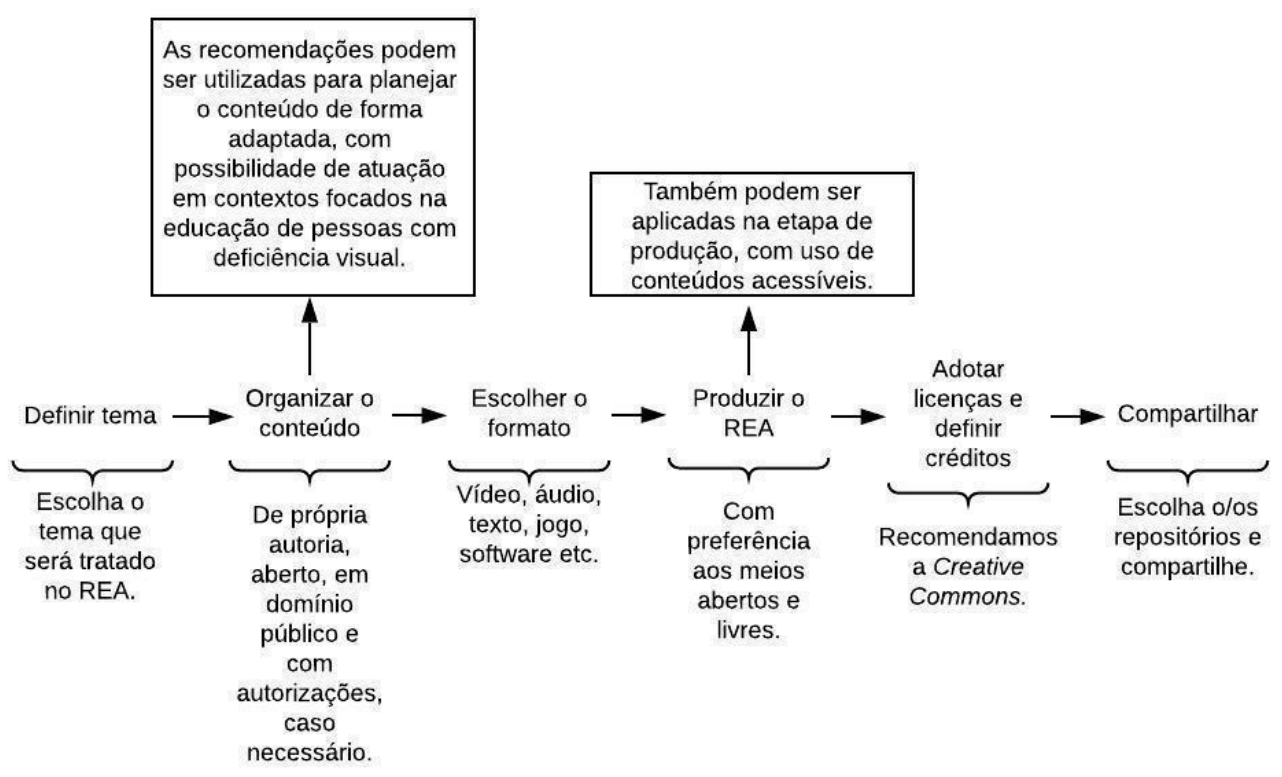

Figura 1. Linha do tempo para desenvolvimento de um REA Fonte: Adaptado de Mazzardo et. al (2019).

\section{Metodologia}

Essa pesquisa é exploratória, de caráter aplicado e aborda questões qualitativas e quantitativas (SILVEIRA e CÓRDOVA, 2009). O desenvolvimento do estudo foi delineado com base nos seguintes passos: (1) levantamento bibliográfico; (2) elaboração de recomendações de acessibilidade primárias para o desenvolvimento de REAs voltados às pessoas com deficiência visual; (3) criação e execução de duas avaliações para melhoria das recomendações; (4) redesign das recomendações, com base nas avaliações realizada na etapa anterior; (5) elaboração de um REA com base nas recomendações e avaliação do recurso desenvolvido. 
O levantamento bibliográfico desenvolvido neste trabalho teve como base os portais Google Acadêmico, SciELO e Portal de Periódicos da CAPES entre abril/2020 e junho/2020. Os resultados possibilitaram análise acerca do estado da arte e formação de referencial para elaboração das primeiras recomendações. Para localizar os estudos relevantes e que estivessem de acordo com o tema proposto pela pesquisa, as seguintes palavras-chave foram utilizadas: "REAs", "Recursos Educacionais Abertos", "Diretrizes de acessibilidade", "Recomendações de acessibilidade", "Acessibilidade", "Tecnologias na Educação" e "Pessoas com deficiência visual".

Os itens encontrados durante a construção da base de fontes de informação destacaram os principais meios para adaptação dos conteúdos, sendo estes o tato, o olfato e a audição, que puderam confirmar suposições observadas empiricamente pelos pesquisadores. Por considerar atual e relevante, foi adicionada uma seção de nome "digitais" que relaciona recomendações para produção de artefatos web e demais sistemas computacionais, de caráter aberto, para pessoas com deficiência visual. A seção de recursos digitais se baseou exclusivamente nas diretrizes da WCAG 2.1 e em materiais didáticos do IBC. (WCAG, 2018). O conjunto da WCAG também colaborou na organização e estrutura do trabalho, com descrição para cada nicho, numeração e informações para aplicação.

Assim, com base no levantamento bibliográfico realizado, uma primeira versão das recomendações de acessibilidade para o desenvolvimento de REAs voltados às pessoas com deficiência visual foi criada.

A partir desta versão, deu-se início à fase de criação e execução de uma avaliação por meio de um questionário on-line. Inicialmente, o instrumento de coleta de dados passou por um teste piloto, a fim de verificar possíveis falhas e melhorias. Assim, o próximo passo foi submeter o documento a um grupo de três profissionais da área de educação, computação e deficiência visual pelo Formulários do Google. O Avaliador 1 é Licenciado em Ciências Biológicas e Especialista em Educação Tecnológica de Jovens e Adultos, atuando há mais de 6 anos na educação de pessoas com deficiência visual e na educação de indígenas. O Avaliador 2 é Licenciado em Pedagogia, Mestre em Educação e atua como professor da rede municipal de ensino de duas cidades, sendo que nos dois ambientes possui alunos com deficiência visual e utiliza desde a formação em Pedagogia REAs na sala de aula. O Avaliador 3 é Bacharel em Sistemas de Informação e Mestrando em Ciências da Computação e Matemática Computacional, com experiência em REAs e Internet das Coisas.

Após a primeira análise e modificações correspondentes, às recomendações foram submetidas a uma nova avaliação a fim de compreender os aspectos da acessibilidade. O Avaliador 4, responsável pela etapa, é cego e tem experiência em produção de materiais e recursos acessíveis, por ter trabalhado na Secretaria de Educação à Distância $(\mathrm{SEaD})$ de uma Universidade Federal no Estado de São Paulo. O Avaliador 4 descreveu suas impressões por mensagens de áudio, em entrevista semiestruturada, pelo WhatsApp.

Por fim, com as recomendações avaliadas e reformuladas de acordo com as sugestões de melhoria dos especialistas, um REA foi produzido levando em consideração algumas das recomendações propostas como resultado do trabalho. O recurso foi enviado a um aluno de 14 anos, cego, estudante do ensino fundamental - anos finais, com o intuito de colher suas impressões acerca dos aspectos em torno do recurso.

O questionário da primeira avaliação contou com questões abertas e fechadas e foi organizado em 19 questões obrigatórias (Escala Likert de cinco pontos - discordo totalmente a concordo totalmente) e 20 questões textuais não obrigatórias. Os tópicos do questionário foram: (1) perfil do usuário; (2) considerações acerca da estrutura e construção do conteúdo das recomendações, visando analisar sua integridade e assertividade; (3) informações sobre as formas 
de aplicação em contexto, se são satisfatórias e bem construídas; (4) questões acerca da acessibilidade dos conteúdos, se o conteúdo das recomendações possibilita o uso por pessoas com deficiência visual; (5) relação entre o processo de ensino-aprendizagem e as recomendações, entendendo os efeitos; (6) questões sobre os materiais utilizados, se são adequados ao uso.

O instrumento supracitado foi desenvolvido com base nos trabalhos de Oliveira e Bernardon (2008) e Silveira et al. (2012), que se sustentaram em Cooper et. al e Nielsen e Molich (1990), respectivamente. A escolha por três especialistas para avaliação deve-se às indicações para avaliação heurística apresentadas por Nielsen e Molich (1990), confirmadas por Rosa e Veras (2013), quando da avaliação de dois websites jornalísticos de acordo com as heurísticas propostas pelos primeiros autores. De acordo com o observado na pesquisa mencionada e no recomendado por Nielsen e Molich (1990), ao utilizar de três (3) a cinco (5) avaliadores para análise do contexto, há possibilidade de alcançar até $75 \%$ dos problemas existentes. Além disso, a experiência dos avaliadores e a análise com base em um conjunto de regras foram considerados neste trabalho (MACIEL et al., 2004).

Com base nos resultados da avaliação e, iniciando a etapa de redesign das recomendações, algumas questões apresentadas por Silveira et al. (2012) foram aplicadas, uma vez que a pesquisa abordou a elaboração de recomendações para produção de objetos educacionais. Deste modo, os pontos considerados foram: (1) conteúdo e aplicação das perguntas ao contexto; (2) resultados para aplicação; (3) considerações sobre o instrumento, que se relacionam com os pontos próprios da pesquisa; (4) restrição do público da pesquisa; (5) estrutura e construção das recomendações; (6) verificação de possibilidades de aplicação das recomendações; (7) questões de acessibilidade das recomendações; (8) questões que envolvem o processo de ensino-aprendizagem em relação às recomendações; (9) materiais utilizados na construção das recomendações.

Em contexto semelhante, o avaliador 4 recebeu o documento com as recomendações de acessibilidade e informou suas impressões sobre o material por meio de uma entrevista semiestruturada. Com as críticas, elogios e sugestões de mudança, as recomendações foram novamente revisadas e um último conjunto de recomendações foi formulado.

Levando em consideração a última versão das recomendações, um recurso em duas partes foi produzido para exame da efetividade do trabalho, sendo a primeira parte em formato podcast e a segunda em formato físico. O REA teve como objetivo atender principalmente questões digitais e computacionais e, seguindo os objetivos/propostas da Base Nacional Comum Curricular (BNCC) para o ano escolar e faixa etária do aluno. $\mathrm{O}$ artefato seguiu a proposição das recomendações 6.1.1, tratando da identidade dos objetos, 6.1.3, sugerindo uso de materiais como argila e massa de modelar, 6.1.4, permitindo a experimentação antecipada, 6.1.11, informando sobre aplicação de diferentes texturas no material, 6.2.1 e 6.2.4, descrevendo a forma e possibilidade de produção de um podcast e 6.4.12, propondo tamanhos de fontes para impressão com atenção ao público de deficientes visuais.

A unidade temática, objetos de conhecimento, habilidades, tema e materiais utilizados para produção da atividade foram, respectivamente: (1) vida e evolução; (2) diversidade de ecossistemas e fenômenos naturais e impactos ambientais; (3) EF07CI07 e EF07CI08 (códigos de algumas das habilidades necessárias para o ano escolar do avaliador, conforme Base Nacional Comum Curricular); (4) biomas brasileiros; (5) argila, miçangas, folhas, palito de picolé e computador com auto falantes e microfone.

\section{Conjunto Preliminar das Recomendações de Acessibilidade REAs}

Conforme descrito anteriormente, a primeira versão das recomendações de acessibilidade para REAs foi elaborada com base na pesquisa bibliográfica em documentos que descreviam atividades 
de ciências da natureza, linguagens, matemática e ciências humanas, em contextos da educação infantil, de ensino fundamental, médio e cursos de curta duração. Na revisão, foram identificados pontos comuns na construção dessas atividades, que orientaram as escolhas quanto aos materiais, métodos e cuidados no desenvolvimento e aplicação de uma tarefa para uso por uma pessoa com deficiência visual. Dessa forma, inicialmente, as recomendações foram estruturadas da seguinte maneira:

1) Organização por recomendações relacionadas ao Tato, Audição e Olfato, bem como as recomendações Digitais.

2) Numeração da recomendação e sua descrição em formato semelhante ao WCAG 2.1. Como mostrado nos exemplos abaixo:

- Recomendação 13: Ao produzir um REA com muitas cores, utilize texturas para desenvolver uma alternativa.

- Recomendação 18: Elabore atividades utilizando pedras, garrafas, tampas, papel entre outros materiais recicláveis.

Este conjunto de recomendações preliminar foi avaliado por especialistas da área de educação, computação e acessibilidade, conforme exposto na metodologia. A avaliação contribuiu para a elaboração de uma versão mais atualizada, adequada ao uso e completa. A próxima seção apresenta a avaliação dos especialistas, sendo a primeira dos profissionais ligados à computação, educação e deficiência visual e a segunda parte do profissional ligado à produção de materiais acessíveis e acessibilidade web.

\section{Resultados das avaliações por especialistas}

A avaliação da primeira versão das recomendações foi realizada por meio do Formulários do Google e ficou disponível pelo período de duas semanas. Os gráficos com as respostas estão disponíveis no Google Drive.

O foco, conforme especificado no formulário, eram profissionais de educação que tivessem experiência com REAs e/ou educação de pessoas com deficiência visual e computação. Com isso, os três especialistas participantes auxiliaram com considerações a respeito das recomendações criadas.

A segunda etapa da análise foi realizada por meio de entrevista semiestruturada via WhatsApp, incluindo o envio das recomendações e devolutiva do avaliador. O objetivo desta etapa foi compreender, no olhar de uma pessoa com deficiência visual e com experiência em produção de materiais acessíveis, quais aspectos poderiam ser melhorados no trabalho para se adequar ao público-alvo da pesquisa. Dessa forma, após estudar as recomendações, o avaliador apresentou sugestões, críticas e elogios acerca da pesquisa, que colaboraram para sua construção final.

Desta maneira, na Seção 5.1 são apresentados os resultados referentes à primeira parte da avaliação, considerando as respostas dos três especialistas. Os gráficos estão em Escala Likert de 5 pontos, conforme questionário do Formulários do Google e seguem a seguinte estrutura: 1 para discordo totalmente, 2 para discordo, 3 para não concordo nem discordo, 4 para concordo e 5 para concordo totalmente.

Por fim, na Seção 5.2 foram reproduzidas as principais considerações do Avaliador 4 e as mudanças resultantes das suas sugestões. Além disso, informa sobre as modificações no documento para atender aos requisitos de leitura para pessoas com deficiência visual que utilizam programas de leitura de tela. 


\subsection{Primeira avaliação}

A avaliação mostrou que $66,7 \%$ responderam que concordam totalmente que as recomendações são claras e objetivas, enquanto 33,3\% concordam (Figura 2). Além disso, todos os participantes afirmaram que existe uma relação entre o resultado e o propósito do estudo. Os resultados também foram positivos no que se refere ao uso de estudos científicos utilizados nas recomendações.

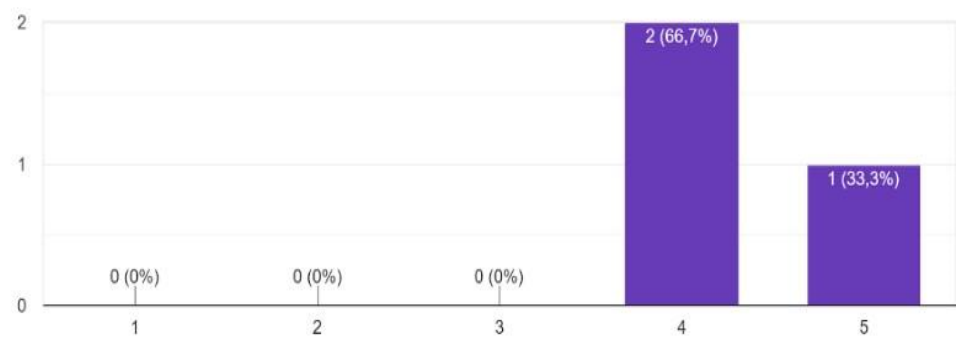

Figura 2. Escrita clara e objetiva das recomendações. Fonte: Acervo do autor.

Em relação à aplicação das recomendações, os seguintes pontos foram destacados: (1) o acesso à localização dos materiais; (2) a facilidade de uso das recomendações; (3) a variedade de contextos de uso educacional. A Figura 3 apresenta que em relação ao primeiro ponto, os especialistas tiveram opiniões diferenciadas, porém em sua maioria de maneira positiva. Quanto à facilidade de uso das recomendações, as respostas também se mantiveram diferentes $(33,3 \%$ para não concordo, não concordo e nem discordo e concordo, respectivamente). Por fim, os avaliadores concordaram que as recomendações são variadas e abordam os diferentes contextos educacionais.

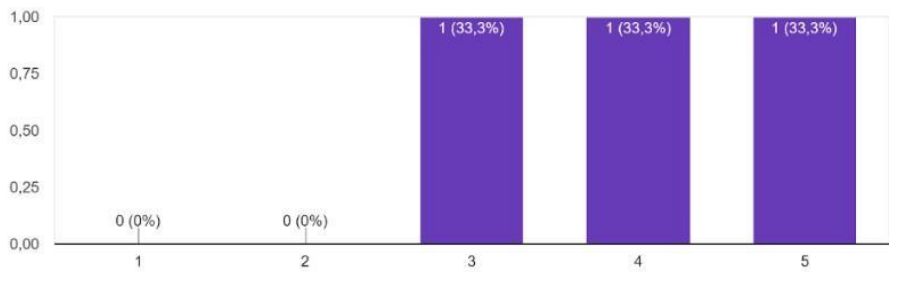

Figura 3. Fácil acesso e localização das recomendações.

Fonte: Acervo do autor.

Questões sobre a acessibilidade das recomendações também foram consideradas. Todos os especialistas concordaram que as recomendações consideram diferentes necessidades da pessoa com deficiência visual. As respostas também foram positivas para a possibilidade de uso de ferramentas para a construção e adaptação de REAs, bem como para a exploração de diversos sentidos utilizando as recomendações $(33,3 \%$ - em discordo, concordo e concordo totalmente e $100 \%$ para concordo, respectivamente). Entretanto, um dos pontos a serem considerados nesta etapa da avaliação foi a necessidade de melhorias no texto, de maneira a possibilitar que uma pessoa com deficiência visual possa fazer uma das recomendações para ensinar uma outra pessoa, também com deficiência. Neste caso, seria necessário mais detalhamento das ideias em cada uma das recomendações.

Sobre o processo de ensino-aprendizagem, $66,7 \%$ concordaram que as recomendações podem ser trabalhadas de forma interdisciplinar. O resultado também foi positivo no que diz respeito à cooperação entre alunos e professores ao utilizar as recomendações (um especialista concordou e outro concordou totalmente com a afirmação). 
Todos os especialistas concordaram que as recomendações auxiliam no desenvolvimento de REAs para que estes sejam melhor construídos ou adaptados para pessoas com deficiência visual (Figura 4).

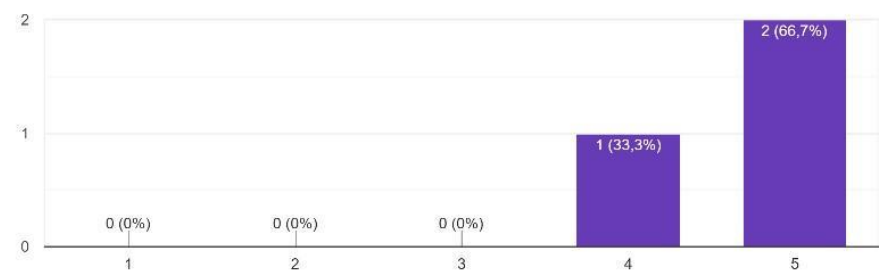

Figura 4. As recomendações auxiliam no processo de desenvolvimento de REAs acessíveis.

Fonte: Acervo do autor.

O questionário tratou sobre os materiais utilizados para a produção dos REAs. Os especialistas se mostraram positivos em relação ao uso de materiais atuais para o desenvolvimento dos REAs e sobre o fato de os materiais serem recicláveis $(66,7 \%$ concordaram com essas afirmações). A última seção obrigatória mediu acerca dos materiais referenciados nas recomendações, sendo a primeira questão relacionada às formas e materiais de trabalho, se são atualizados. Em relação à aplicação dos materiais e recursos para questões específicas de conteúdo, para o desenvolvimento cultural e social do indivíduo, os especialistas apresentaram respostas diferenciadas, mas em sua maioria positivas (conforme a Figura 5).

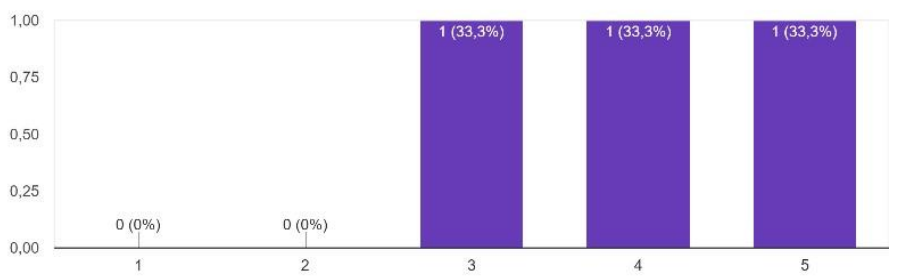

Figura 5. Materiais e recursos utilizados para o desenvolvimento cultural e social do indivíduo Fonte: Acervo do autor.

Quanto à segurança dos materiais escolhidos para utilização, 66,7\% dos participantes se mostraram a favor das escolhas.

A última questão aberta do questionário foi respondida por um especialista que fez o seguinte comentário:

"O trabalho está bom e cumpre bem o que objetiva dentro de muitas condições que os deficientes visuais e baixa visão precisam. Sempre bom lembrar que a convivência traz um relacionamento frutífero entre educadores educados. Nestes casos, o aprender com os alunos leva ao maior sucesso em todo o trabalho nas realidades diferenciadas dos alunos".

Os resultados da avaliação foram em sua maioria positivos, conforme pode ser visto na Figura 6. 


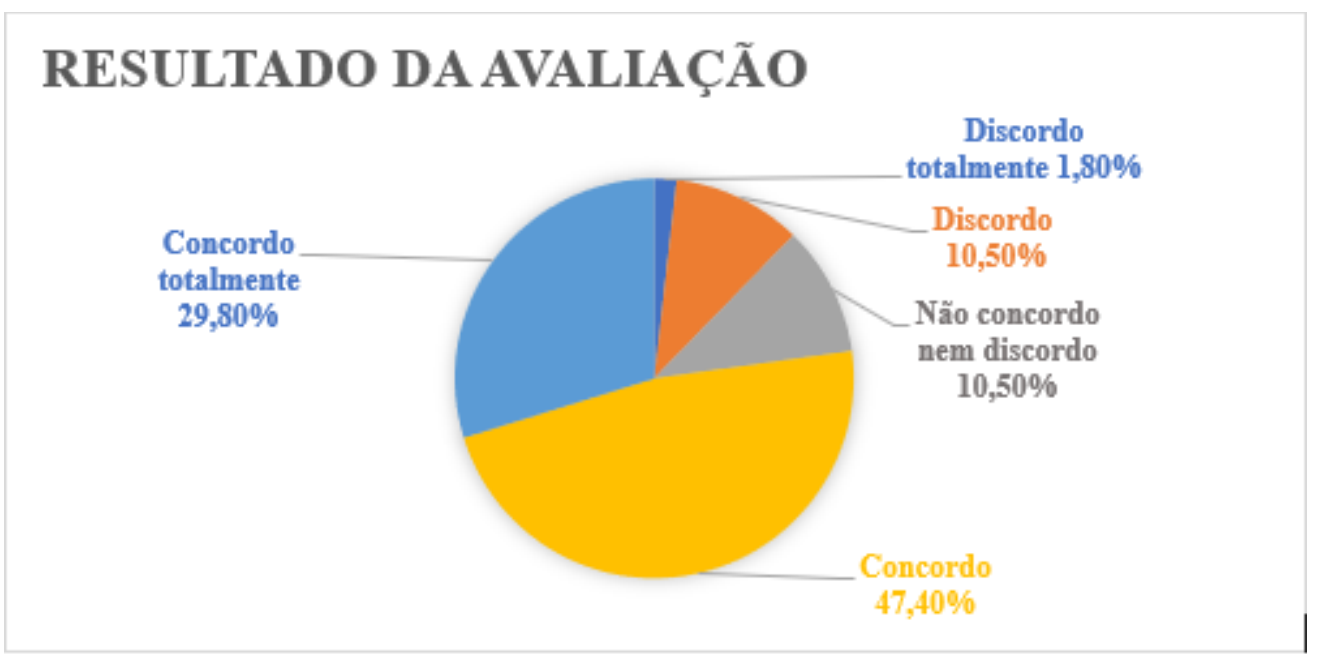

Figura 6. Respostas do questionário de avaliação.

Fonte: Acervo do autor.

Entretanto, conforme destacado na seção anterior, alguns comentários foram apresentados pelos especialistas e, estes, foram avaliados pelos pesquisadores para possíveis alterações das recomendações. Sendo assim, os seguintes pontos foram modificados:

1. Imagens foram inseridas a fim de facilitar o entendimento da aplicação da recomendação;

2. alguns textos foram reorganizados e reescritos para que ficassem mais claros para os profissionais;

3. foram adicionadas referências bibliográficas diferenciadas para que os profissionais pudessem consultar o material original;

4. no caso de recomendações que utilizam materiais perigosos, um aviso foi inserido para que a atividade seja realizada com a supervisão de adultos.

Um ponto citado pelos especialistas diz respeito a atualização do referencial teórico, com trabalhos de mais de 10 anos citados nas recomendações. Apesar dos trabalhos serem considerados "antigos", a busca realizada nas bases de dados apresentou diversos trabalhos importantes e de conteúdo primordial para este estudo, por isso foram considerados. Além disso, é importante lembrar que a escola ainda trabalha com muitas produções manuais, quase artesanais. Desse modo, se as recomendações fossem exclusivamente digitais ou utilizassem unicamente recursos tecnológicos, poderiam não atender toda a comunidade escolar, principalmente as escolas públicas.

Assim, com base na avaliação realizada e nos diversos comentários apresentados pelos especialistas, uma nova versão das recomendações foi proposta e avaliada na segunda parte do processo.

\subsection{Segunda avaliação}

Conforme destacado, foi realizada uma entrevista semiestruturada on-line, em que o avaliador expôs suas impressões sobre o conjunto de recomendações proposto. Assim, levantou alguns pontos de atenção às mudanças para adequação das recomendações ao público de pessoas com deficiência visual, informou sobre pontos equivocados e sugeriu pesquisa/inclusão de pontos não considerados pelos autores. Os destaques foram: 
1. Dividir as recomendações entre público com baixa visão e público cego, garantindo a aplicação ao perfil adequado pelo profissional que atua na educação das pessoas com deficiência visual;

2. explicar melhor os objetivos das recomendações, considerando quem irá utilizá-las e o objetivo de cada uma das recomendações;

3. incluir recomendações voltadas ao público de pessoas cegas na seção "Digitais" e não apenas sugestões voltadas ao público de pessoas com baixa visão;

4. inserir recomendações sobre utilização de cadernos com pauta ampliada, uso de impressora 3D para fabricação de materiais e utilização de objetos em pequena escala para experimentação tátil do cego;

5. descrever/reformular o texto das recomendações: (1) 6.1.11 Confeccione cadernos com 2 lados diferentes, sendo um voltado à pessoa com deficiência visual e outro à pessoa sem deficiência visual (PRETO, 2009); (2) 6.1.12. Utilize gabaritos de palito de picolé para orientar a escrita e o desenho do indivíduo com deficiência visual.

Com base no ponto 1 da análise do especialista, foi inserido em cada recomendação um breve comentário sobre o público sugerido de uso, sendo que, nos casos em que a recomendação tinha foco nos dois maiores grupos, as pessoas cegas e com baixa visão, foi mantido apenas o termo relacionado a deficiência visual ou não foi mencionado um perfil individual. Levando em consideração o ponto 2 , as recomendações foram revisadas para que pudessem ser mais claras e objetivas, além da inclusão do $2^{\circ}$ parágrafo na Seção 6 indicando o perfil do usuário. Sobre o tópico 3, foram adicionadas novas recomendações que atendessem à observação do especialista. No ponto 4, foram inseridas duas novas recomendações tratando do caderno e dos objetos em baixa escala. Quanto ao ponto 5, optou-se pela remoção da recomendação 6.1.12 e reformulação da recomendação 6.1.11.

Além das sugestões para melhoria, o avaliador destacou positivamente as recomendações 6.1.3 e 6.2.5 e indicou que o trabalho tem importância ímpar para ajudar os alunos com deficiência visual levando em consideração as diversas dificuldades que enfrentam no seu cotidiano.

Por fim, o trabalho foi revisado e o conjunto de recomendações também passou por mudanças para promover acessibilidade por meio de leitores de tela. Desse modo, as seções do trabalho foram categorizadas em título, subtítulo e texto normal (seguindo as recomendações 6.4.8), os campos de descrição de imagens/figuras foram preenchidos (seguindo as recomendações 6.4.7) e o documento foi organizado de forma linear (seguindo as recomendações 6.4.6).

\section{Resultado - Recomendações de Acessibilidade para REAs}

A busca pela elaboração de um conjunto de recomendações para o desenvolvimento de REAs acessíveis à educação de pessoas com deficiência visual norteia-se pela separação dos segmentos que o tema reúne. Portanto, as recomendações aqui expostas foram divididas entre os principais sentidos (tato, audição e olfato), seguido pelos recursos digitais, com as recomendações recuperadas na literatura. Além disso, destaca-se que a elaboração das recomendações seguiu a estrutura da WCAG 2.1 e considerou materiais didáticos do IBC.

Em tempo, destaca-se que o conjunto abaixo pretende auxiliar o profissional (professor, técnico ou apoio escolar) com pouca ou nenhuma experiência na educação de pessoas com deficiência visual para que tenha uma visão inicial das possibilidades de adaptação e elaboração de materiais acessíveis e abertos ao público foco do estudo. 


\subsection{Tato}

O tato na educação de pessoas com deficiência visual é um dos principais meios que pode ser utilizado na interação com o ambiente. É por meio do toque, pelas mãos, pés ou outra região do corpo, que o indivíduo cego ou com visão subnormal pode participar, interpretar e interagir com atividades do dia a dia (Veraszto e Vicente, 2017). Descreve-se, então, de forma estruturada, as recomendações voltadas a soluções envolvendo o tato na educação de pessoas com deficiência visual para produção de REAs.

Recomendação 6.1.1. Dê características únicas aos objetos representados nos REAs visuais. Utilize pontos, textura, relevos em locais específicos, garantindo a identidade do objeto que você deseja representar (ADAM e CALOMENO, 2013; PRETO, 2009).

Recomendação 6.1.2. Não deixe que os elementos visuais se sobreponham nas imagens (ADAM e CALOMENO, 2013). Por serem reconhecidos por meio tátil, esses REAs precisam estar bem separados de modo que um objeto não atrapalhe o outro. Cada objeto tem características próprias e a sobreposição pode tornar difícil a identificação.

Recomendação 6.1.3. Utilize massa de modelar ou argila para representar objetos de pequena ou grande escala nos REAs e auxiliar na percepção do deficiente visual.

Recomendação 6.1.4. Permita a experimentação por parte da pessoa com deficiência visual de forma antecipada se o conteúdo do REA envolver alguma representação gráfica nova (PRETO, 2009; DOMINICI et. al, 2008).

Recomendação 6.1.5. Utilize líquidos como a água, com cuidado a temperatura, para explicar conceitos relacionados ao calor, frio, líquido, gasoso e sólido (CAMARGO e NARDI, 2007). Recorrendo a água, evita-se possíveis riscos em indivíduos alérgicos a elementos mais específicos.

Recomendação 6.1.6. Evite elementos com muito contraste ou iluminação exagerada ao elaborar uma atividade (RUSSELL-MINDA et.al, 2007; CHUNG, 2002). Dependendo do contexto, isso pode inutilizar o REA, que ficará com pouca qualidade devido às questões técnicas de impressão. Apesar disso, lembre-se que o público de pessoas com baixa visão, por outro lado, pode se beneficiar do contraste elevado. Se houver interesse, verifique em um verificador de contrastes se o seu REA está adequado.

Recomendação 6.1.7. Não construa REAs com elementos visuais como, por exemplo, desenhos, gráficos e figuras muito complexas. Procure utilizar linhas e pontos como contorno, sem preenchimento interno (ADAM e CALOMENO, 2013). A Figura 7 mostra uma figura complexa que, se fielmente representada por meio tátil, poderá proporcionar uma experiência confusa ao leitor com deficiência visual. 


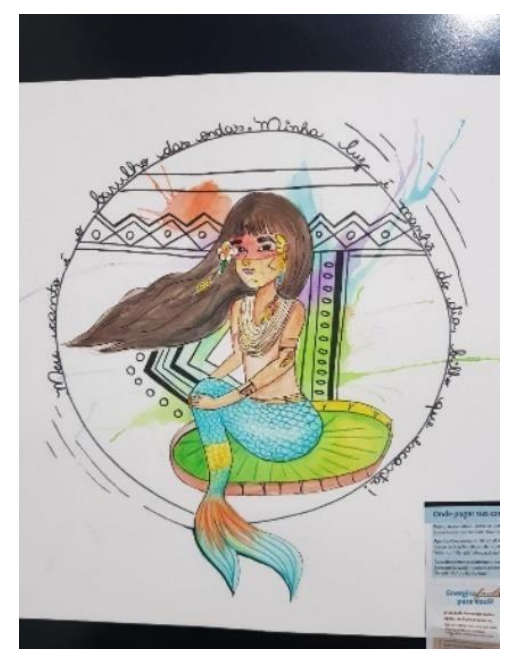

Figura 7. Técnicas em aquarela: Iara - Por: Bianca Weihs. Fonte: Acervo do autor.

Recomendação 6.1.8. Ao preparar um material REA para deficientes visuais, faça-o com material vegetal 90 boleado com caneta sem tinta (ADAM e CALOMENO, 2013), tinta relevo, barbante, linhas de costura, papel para desenho, alfinetes, EVA e papel alumínio - Figura 8 (DOMINICI et al. 2008).

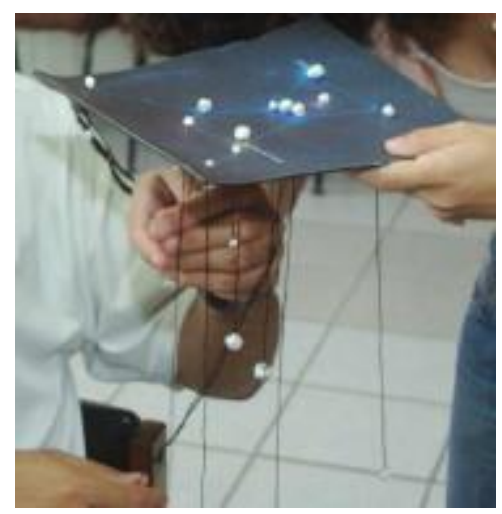

Figura 8. Constelação de Órion em 3D. Fonte: DOMINICI et al, 2008.

Recomendação 6.1.9. Produza material com fundo preto e tinta dourada quando criar uma atividade voltada à pessoa com visão subnormal - Figura 9 (DOMINICI et al. 2008).

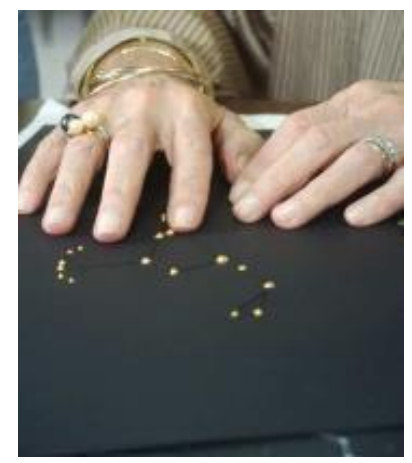

Figura 9. Tinta relevo dourado em papel cartão. Fonte: DOMINICI et. al, 2008. 
Recomendação 6.1.10. Confeccione cadernos com dois lados diferentes, sendo um voltado à pessoa com deficiência visual e outro à pessoa sem deficiência visual - Figura 10 (PRETO, 2009). Para isso, considere utilizar textos pequenos, visando escrita com reglete e punção ou, quando possível, uma impressora em braille.

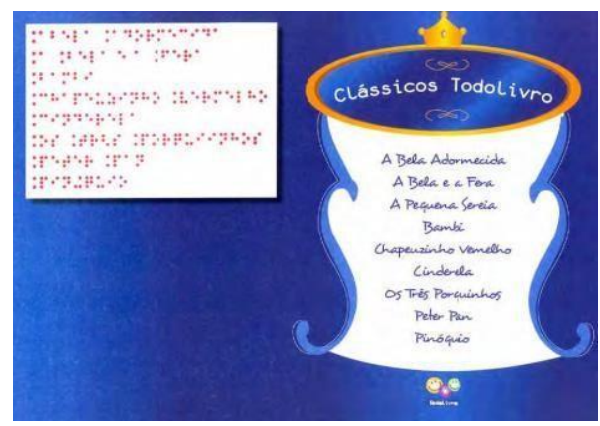

Figura 10. Caderno de dois lados. Fonte: PRETO, 2009.

Recomendação 6.1.11. Ao produzir um REA com muitas cores, utilize texturas para desenvolver uma alternativa ao indivíduo cego - Figura 12.

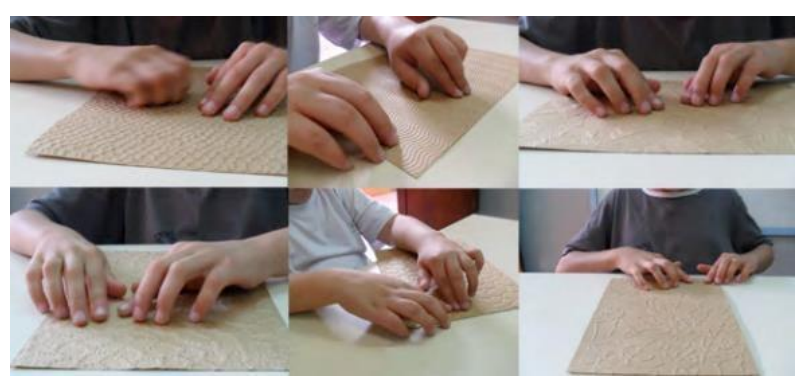

Figura 12. Percepção tátil com papéis texturizados. Fonte: ADAM e CALOMENO, 2013.

Recomendação 6.1.12. Construa/disponibilize objetos em pequena escala como, por exemplo, animais, móveis e imóveis, para que o cego possa tatear e reconhecer.

Recomendação 6.1.13. Utilize caderno com pauta ampliada para facilitar a escrita do indivíduo com baixa visão.

\subsection{Audição}

A audição é uma importante alternativa na construção de atividades acessíveis. A utilização de som é útil em atividades que vão de física até português, conforme destacam Camargo e Nardi (2007). Destaca-se nesta seção, portanto, importantes soluções em forma de recomendações para adaptação de conteúdos e construção de REAs adequados ao uso por parte das pessoas com deficiência visual.

Recomendação 6.2.1. Crie material em áudio, no formato de podcast, sobre assuntos diversos tratados em sala ou fora dela em um diretório único, genérico, para ser compartilhado como REA (JUNIOR e COUTINHO, 2009; FREIRE, 2010).

Recomendação 6.2.2. Produza material em áudio descrevendo todas as atividades escritas e visuais que foram criadas em um diretório único para ser compartilhado como REA. 
Recomendação 6.2.3. Forneça audiodescrição de qualidade se seu REA possuir vídeos (LIBERA e JUNIOR, 2021).

Recomendação 6.2.4. Ao produzir um REA em áudio, evite efeitos sonoros agudos, graves e simultâneos a fala do interlocutor.

Recomendação 6.2.5. Elabore atividades utilizando pedras, garrafas, tampas, papel entre outros materiais recicláveis. A Figura 13 mostra um exemplo de como essa técnica pode ser aplicada.

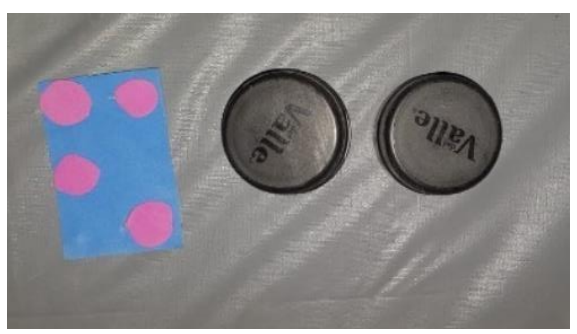

Figura 13. Jogo da memória com pedras e cédula braille com papelão. Fonte: Acervo do autor.

\subsection{Olfato}

Apesar de importante meio para adaptação das atividades, o olfato ainda é pouco explorado. Não são muitas as referências e pesquisas acerca da sua utilização em atividades para crianças e adolescentes, o que a torna, assim como o paladar, um sentido ainda a ser pesquisado com maior profundidade. Assim, aqui estão expostas as soluções recuperadas e percebidas para exploração do olfato em REAs voltados a pessoas com deficiência visual.

Recomendação 6.3.1. Crie atividades que utilizem diferentes aromas para elementos distintos de forma a possibilitar ao aluno interagir com todos os elementos e realizar experimentos com esses (NUNES et al. 2010).

Recomendação 6.3.2. Utilize aromas de ambientes para criar atividades que trabalhem locais que o indivíduo não conhece, mostrando as características, por meio do olfato, de um local específico (ARRUDA, 2016).

Recomendação 6.3.3. Utilize aromas para trabalhar questões alimentares sobre o que é ou não saudável.

\subsection{Digitais}

Por serem importantes guias no desenvolvimento de sistemas web e produção de materiais acessíveis, conforme evidenciado nessa pesquisa, as recomendações a seguir destacam adaptações de algumas diretrizes da WCAG 2.1 e de alguns materiais didáticos do IBC voltados a pessoas com deficiência visual e que podem ser utilizadas no contexto da produção de um REA e não somente na confecção de uma página web ou materiais específicos/isolados.

Recomendação 6.4.1. Não utilize em um vídeo mais de três flashs geral ou vermelho por segundo (WCAG, 2018).

Recomendação 6.4.2. Determine mensagens descrevendo o contexto/situação caso o seu REA seja um software com interação (WCAG, 2018).

Recomendação 6.4.3. Evite animações em seu REA se ele for um software (WCAG, 2018). 
Recomendação 6.4.4. Não estipule tempo em softwares ou jogos, assim torna possível a leitura e interpretação do usuário independentemente se utiliza um software de leitura ou possui baixa visão (WCAG, 2018).

Recomendação 6.4.5. Forneça feedback constante ao usuário de forma a mantê-lo informado do que ocorre no processamento (WCAG, 2018).

Recomendação 6.4.6. Mantenha sua página linear e organizada suficientemente bem para leitura e navegação facilitada do deficiente visual (WCAG, 2018) - Figura 14.

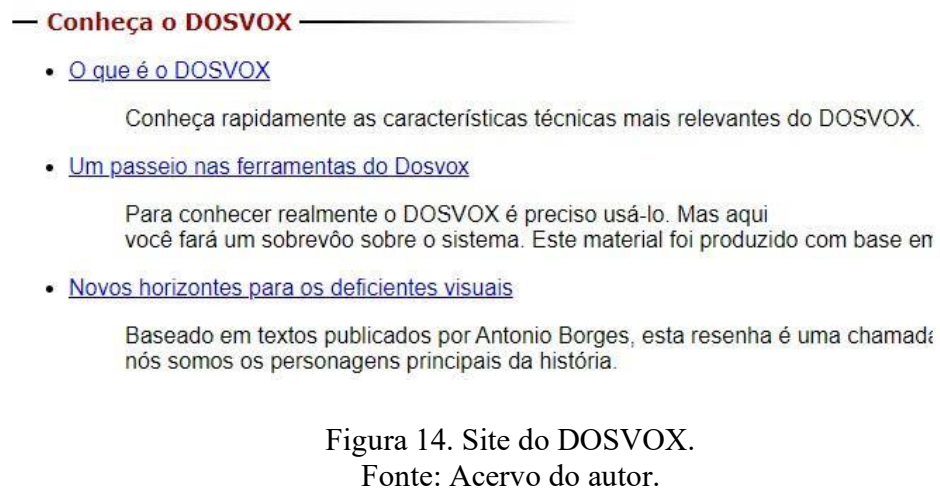

Recomendação 6.4.7. Crie atividades com alternativas a textos escritos em método tradicional e imagens. Também descreva os itens do seu software (WCAG, 2018). A Figura 15 exemplifica uma postagem, com descrição de imagem em formato textual.

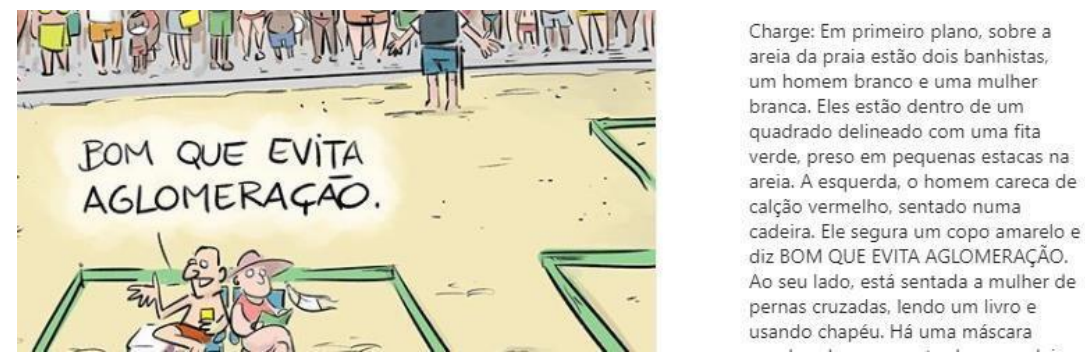

Figura 15. Postagem e descrição da imagem. Fonte: Acervo do autor.

Recomendação 6.4.8. Ao construir um documento, determine o tipo do seu texto, se é um título, um subtítulo ou um parágrafo, facilitando a leitura do indivíduo cego utilizando leitores de tela (LIBERA e JUNIOR, 2021).

Recomendação 6.4.9. Não utilize designs diferenciados em seus REAs. Fontes muito elaboradas, com serifas e tamanhos pequenos demais em atividades podem prejudicar o leitor cego e com baixa visão (RUSSELL-MINDA et.al, 2007; CHUNG, 2002; DOMINICI et al. 2008).

Recomendação 6.4.10. Dê preferência às fontes Tahoma, Verdana, APhont (KITCHEL, 2019 apud LIBERA e JUNIOR, 2021) e Arial (LIBERA e JUNIOR, 2021) em materiais para pessoas com baixa visão.

Recomendação 6.4.11. Para REAs que envolvam apresentações em slides, utilize fonte de no mínimo 32pt (LIBERA e JUNIOR, 2021), considerando o público com baixa visão. 
Recomendação 6.4.12. Caso o REA seja impresso, considere utilizar fonte entre 18pt e 24pt para facilitar a leitura por pessoas com baixa visão (LIBERA e JUNIOR, 2021).

Recomendação 6.4.13. Quando destacar uma informação no seu documento, faça de maneira textual e não somente com cores ou efeitos de destaque (LIBERA e JUNIOR, 2021). A Figura 16 mostra como deve ser para que a pessoa cega consiga compreender a informação.

\section{Relação de turmas e horários (turmas lotadas em vermelho) Segundas e quartas de manhã (turma lotada) Segundas e quartas à tarde (turma lotada) Terças e quintas de manhã (turma com vagas) Terças e quintas à tarde (turma com vagas)}

Figura 16. Destacando informações de maneira textual. Fonte: LÍBERA e JÚNIOR, 2021.

Recomendação 6.4.14. Ao inserir um link no texto de algum REA para a pessoa cega, não o deixe no formato original, com números, símbolos e letras. Ao invés disso, camufle-o em um hyperlink (LIBERA e JUNIOR, 2021) - Figura 17.

Você pode aprender a criar documentos acessíveis no curso Técnicas para Criacão de Documentos Diqitais Acessíveis aplicadas à Deficiência Visual.

Figura 17. Utilizando hyperlinks. Fonte: LÍBERA e JÚNIOR, 2021.

Recomendação 6.4.15. Considere inserir um sumário, caso seja um documento extenso, para auxiliar na navegação do deficiente visual no documento (LIBERA e JUNIOR, 2021) utilizado no REA.

\section{Aplicação das recomendações}

As recomendações de acessibilidade aqui propostas, embora sustentadas em referencial plural e consistente, demandam avaliação pelo público-alvo do trabalho, as pessoas com deficiência visual. Portanto, com base nas recomendações 6.1.1, 6.1.3, 6.1.4, 6.1.11, 6.2.1 e 6.2.4 (citadas anteriormente), foi produzido um REA para o ensino de ciências, com foco nos biomas brasileiros, utilizando o formato podcast e um material físico tátil. O objetivo da junção dos diferentes tipos de artefatos foi utilizar conceitos de tecnologia/computacionais integradas aos materiais físicos, com intuito de destacar as diferentes possibilidades dessa combinação.

Os materiais do REA foram entregues ao aluno, respectivamente, via WhatsApp e presencialmente. Além disso, o REA foi disponibilizado no repositório EduCAPES em endereço único, com o podcast, orientação para produção do material tátil e imagem do material físico produzido para esta etapa da pesquisa.

\subsection{O REA}

O podcast foi produzido na ferramenta Anchor, do Spotify, com efeitos sonoros gratuitos e cedidos pela plataforma. Com duração de pouco mais de oito minutos, primeiro foram apresentados o podcast, o autor e a temática. Após a introdução, foram explanados o conceito e 
características dos biomas brasileiros. Ao fim, o aluno é instigado a tatear o material, que obrigatoriamente deve acompanhar o podcast, e compreender o explicado anteriormente. $\mathrm{O}$ objetivo do podcast foi expor ao indivíduo a teoria acerca da temática, integrando-a à prática, com o artefato físico.

O material tátil (Figura 18), produzido com argila, foi moldado seguindo a silhueta do território brasileiro, dividindo as regiões dos biomas com uma grossa linha. Para cada bioma, uma textura diferente foi aplicada, sendo ondulações, círculos pequenos, círculos grandes, texturas ásperas e lisas. $\mathrm{O}$ intuito do material foi proporcionar ao aluno a compreensão tátil do que foi exposto em áudio, visto sua não possibilidade de experimentação pela visão.

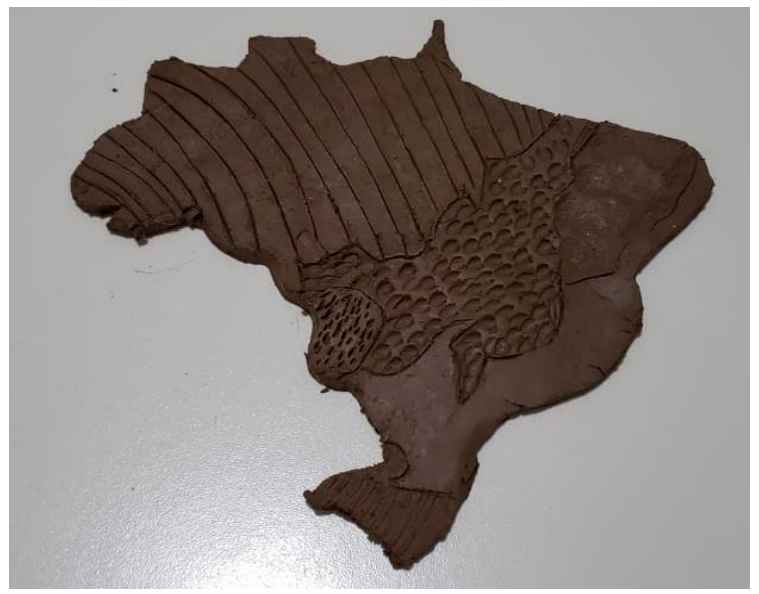

Figura 18: Biomas brasileiros em modelo tátil. Fonte: Acervo do autor.

\subsection{Avaliação do REA}

Para colher as impressões do avaliador foram feitas perguntas em torno das recomendações, a fim de compreender se os aspectos aplicados ao REA foram percebidos positivamente durante a utilização do material. Por último, o indivíduo foi indagado sobre sugestões, críticas ou elogios acerca do recurso.

Na primeira etapa da avaliação, foi questionado sobre as recomendações 6.1.1 e 6.1.11. O objetivo foi compreender se a textura e relevo do material, em junção ao podcast, eram suficientes para o contexto e objetivos da atividade. Em resposta, informou: "Está ótimo, dá para entender. O tátil ajudou bastante, porque se eu passar a mão dá para saber certinho os biomas que você explicou, onde fica cada um deles". Em outro momento, um ponto mencionado entre as palavras do discurso como de atenção para revisão foi o fato da argila ser ondulada, pois, para o avaliador: "Tem hora que fica meio alto nas pontas e não dá de entender bem, mas é coisa pouca". Sobre a observação do avaliador, o fato ocorreu devido a forma de manipulação do material, que acaba resultando em desuniformidade. Por último, expôs sua opinião sobre a utilização dos dois tipos de materiais em uma mesma atividade: "Eu acho até que só podcast já tá bom porque você explicou certinho, bem detalhado e deu pra entender já”. Conforme o comentário, o material físico, apesar de facilitar, de acordo com o avaliador, é dispensável.

Para entender se a argila foi uma boa escolha e se a recomendação 6.1.3 era persistente, o avaliador foi indagado acerca da sua opinião sobre o material utilizado. Assim, explicou: "Eu nunca tinha usado isso não, mas achei bem legal o jeito que ela é". Com intuito de apresentar parte do processo de confecção do objeto e permitir experimentação antecipada pelo deficiente visual, conforme recomendação 6.1.4, o avaliador pôde tatear a argila em seu estado flexível, o que o fez comentar sobre algumas possibilidades com aquele recurso. Por último, levantou que havia alguns pontos afiados e que o material era muito quebradiço: "É meio pontudo e esfarela 
um pouco, mas dá pra entender". O fato de estar quebradiço e afiado são reflexos do autor do recurso não ter manipulado bem a argila e não ter lixado-a ao fim do processo. Para que a argila atinja a textura ideal quando seca, precisa ser amassada por bastante tempo enquanto flexível e, se não for assada em forno específico, demanda lixamento para durabilidade prolongada da peça.

Com olhar sobre as recomendações 6.2.1 e 6.2.4, questionamos ao avaliador se o formato podcast havia o agradado. Respondeu então: "Está legal, você explicou muito bem detalhado, certinho, aí ajudou a entender". Em outro ponto, foi perguntado se os efeitos sonoros bem como altura e tom de voz estavam bem ajustados. De acordo com sua compreensão: "Só o áudio que estava meio baixo, mas não atrapalhou muito não. Mas poderia ser mais alto um pouco". A observação do avaliador reflete na qualidade do microfone utilizado para gravação, que poderia ser mais profissional, do tipo externo ao computador.

A última pergunta foi relacionada a utilização do REA em período escolar. Ao avaliador foi questionado se um programa de podcast semanal, disponibilizado pelo WhatsApp em um grupo específico para os áudios, voltado totalmente aos conteúdos escolares do seu ano escolar, naquele formato, poderia auxiliá-lo em sala de aula. De maneira imediata respondeu: "Ajudaria sim. Ajudaria até outras pessoas também porque tem hora que é bom ver de novo o que o professor explicou pra ter certeza se tá certa”.

\section{Conclusões e Trabalhos Futuros}

Durante a pesquisa bibliográfica acerca dos recursos previamente construídos e sua relação com a educação de pessoas com deficiência visual observou-se que existe boa quantidade de recursos em uma grande diversidade de contextos. O que chama atenção é que a maioria dos trabalhos descreve uma atividade ou área específica de forma aprofundada, possibilitando para aqueles que precisam de uma solução setorizada a localização de um referencial científico.

No caso dos softwares, uma questão importante a ser discutida é o fato de ainda não estarem acessíveis o suficiente para o público pesquisado. Apesar das diretrizes e incentivos, grande parte dos sistemas de acesso aos REAs, e até mesmo parte dos REAs baseados de alguma forma em software, não são pensados para facilidade de adaptação ou utilização sem necessidade de modificação específica para esse público. Ainda, sobre esses sistemas, é importante ressaltar que apesar da falta de disponibilidade e adequação, a realidade tem se alterado significativamente nos últimos anos e caminha para um ambiente favorável, com programas cada vez mais específicos e bem construídos.

No contexto do papel dos REAs na educação das pessoas com deficiência visual, a utilização de REAs é um importante meio para divulgar e possibilitar o desenvolvimento dos indivíduos. O compartilhamento de formas de fazer e de artefatos prontos diminui o tempo de elaboração por parte do profissional da educação e coloca em prática questões validadas em outros contextos e com sucesso evidenciado cientificamente. Nesse sentido, a escola ganha em qualidade no processo de ensino-aprendizagem.

Além das questões de acessibilidade nos sistemas, a falta de recursos financeiros para pesquisa e compra de equipamentos prejudica não só o professor e aluno que utilizam os REAs, mas também o profissional que produz o recurso. Deste modo, a presente pesquisa visa contribuir para este fim, de maneira que os recursos possam ser utilizados de maneira gratuita, atualizados e disponibilizados de forma imediata.

Conforme observado nas avaliações das recomendações, o resultado apresentado pode ajudar os profissionais e alunos com deficiência visual quanto à permanência e qualidade no atendimento educacional prestado, com ênfase ao ambiente da escola pública, ainda carente da maioria dos recursos e conceitos praticados em contextos mais abrangentes. A diversidade de materiais com 
adaptações pontuais ou concebidos com olhar a um desenho universal garante a acessibilidade desse público não só na escola, mas em todos os ambientes da vida em sociedade.

Como trabalhos futuros pretende-se conduzir uma pesquisa prática mais abrangente, utilizando as recomendações em ambientes educacionais, com professores, técnicos e alunos, a fim de compreender a efetividade do material em grande escala e as mudanças necessárias para que atenda da melhor forma tais usuários, colaborando com a inclusão e acessibilidade.

\section{Agradecimentos}

Os autores agradecem às agências de fomento brasileiras: Coordenação de Aperfeiçoamento de Pessoal de Nível Superior (CAPES); Fundação de Amparo à Pesquisa do Estado de São Paulo (FAPESP) - no 2018/26636-2; e CNPq. Agradecemos também a todos os avaliadores e participantes que colaboraram com a pesquisa.

\section{Referências}

Adam, D., \& Calomeno, C. (2013). Metodologia para adaptação de conteúdo editorial imagético para deficientes visuais. In: Revista Brasileira de Design da Informação. São Paulo, 9(3), 201-215. DOI: 10.51358/id.v9i3.142 [GS Search]

Alevizou, G. (2015) From OER to MOOCs: critical perspectives on the historical mediation trajectories of open education. In: International Journal of Media e Cultural Politics, 11(2), 347-378. DOI: 10.1386/macp.11.2.203_1 [GS Search]

Arruda, L. (2016). GEOGRAFIA NA INFÂNCIA PARA ALUNOS COM DEFICIÊNCIA VISUAL: a utilização de uma maquete multissensorial para a aprendizagem do conceito de paisagem. In: Revista Brasileira de Educação em Geografia, Campinas, 6(11), 208-221. DOI: 10.33025/grgcp2.v3i5.1357 [GS Search]

Barros, G., \& Menta, E. (2007). Podcast: produções de áudio para educação de forma crítica, criativa e cidadã. In: Revista de Economía Política de las Tecnologías de la Información y Comunicación, 9(1). [GS Search]

Biblioteca do Instituto de Psicologia (2018, fevereiro). O que são MOOCs (Massive Open Online Courses)? Instituto de Psicologia, Universidade Federal do Rio Grande do Sul. https://www.ufrgs.br/bibpsico/2018/02/o-que-sao-moocs-massive-open-online-courses/

Camargo, E., \& Nardi, R. (2007). Planejamento de atividades de ensino de Física para alunos com deficiência visual: dificuldades e alternativas. In: Revista Electrónica de Enseñanza de las Ciencias, 6(2), 378-401. [GS Search]

Chung, S. (2002). The effect of letter spacing on reading speed in central and peripheral vision. In: Investigative Ophthalmology e Visual Science, 43(4), 1270-1276. [GS Search]

Costa, C., \& Van Munster, M. (2017). Adaptações Curriculares nas Aulas de Educação Física Envolvendo Estudantes com Deficiência Visual. In: Revista Brasileira de Educação Especial, 23(3), 361-376. DOI: 10.1590/s141365382317000300004 [GS Search]

Dominici, T. et al. (2008). Atividades de observação e identificação do céu adaptadas às pessoas com deficiência visual. In: Revista Brasileira de Ensino de Física, 30(4), 4501.1-4501.8. DOI: $10.1590 /$ S0102-47442008000400010 [GS Search] 
Dutra, R., \& Tarouco, L. (2007). Recursos Educacionais Abertos (Open Educational Resources). In: Revista Novas Tecnologias na Educação. 5(1). DOI: 10.22456/1679-1916.14171 [GS Search]

Franco, J., \& Dias, T. (2007). The education of the blind in Brazil. In: Avesso do Avesso, Araçatuba, 5(5), 78-82. [GS Search]

Freire, E. (2010). Construindo um modelo de referência à participação ativa dos sujeitos em projetos educativos em ambiente on-line [Dissertação de mestrado, Universidade Federal do Rio Grande do Norte - UFRN].

Freire, E. (2011). O podcast como ferramenta de educação inclusiva para deficientes visuais e auditivos. In: Revista Educação Especial, Santa Maria, 24(40), 195-206. DOI: 10.5902/1984686X2028 [GS Search]

Hylén, J. (2005). Open Educational Resources: Opportunities and Challenges. In: OECD's Centre for Educational Research and Innovation. [GS Search]

Junior, J., \& Coutinho, C. (2009). Podcast uma Ferramenta Tecnológica para auxílio ao Ensino de Deficientes Visuais. In Anais VIII LUSOCOM (pp. 2114-2126). UluSofona. [GS Search]

Kitchel, J. (2019). APH Guidelines for Print Document Design. American Printing House. https://www.aph.org/aph-guidelines-for-print-document-design/

Leite, P. et al. (2018). Ensino e extensão sobre inclusão digital usando REAs. In Anais XVII Simpósio Brasileiro sobre Fatores Humanos em Sistemas Computacionais. SBC. DOI: 10.5753/ihc.2018.4213 [GS Search]

Líbera, B., \& Júnior, J. (2021). Técnicas para criação de documentos digitais acessíveis. In Curso de Formação Continuada Ferramentas digitais para o ensino remoto com ênfase na deficiência visual. Instituto Benjamin Constant.

Maciel, C. et al. (2004). Avaliação heurística em sítios na web. In Anais VII Escola de informática do SBC-Centro Oeste. SBC. [GS Search]

Mantoan, M. (2003). Inclusão escolar: O que é? Por quê? Como fazer? (1 $1^{\mathrm{a}}$ ed.). Editora Moderna.

Mazzardo, M. et al. (2019). Competências digitais dos professores para produção de recursos educacionais abertos (REA). In: Revista de educação a distância e e-Learning, Portugal, 2(1), 62-78. DOI: 10.34627/vol2iss1pp62-78 [GS Search]

Russell-Minda, E. et al. (2007). The legibility of typefaces for readers with low vision: A Research Review. In: JVIB, 101(7), 402-415. 10.1177/0145482X0710100703 [GS Search]

NCE/UFRJ. (2002). Projeto DOSVOX. UFRJ. http://intervox.nce.ufrj.br/dosvox/

Neto, F., \& Garcia, M. (2013). Recursos educacionais abertos para EAD. In Anais Congresso Brasileiro de Ensino Superior a Distância. UFPA. [GS Search]

Nielsen, J., \& Molich, R. (1990). Avaliação heurística de interfaces de usuário, Proc. ACM CHI'90 Conf. (Seattle, WA, 1-5 de abril), 249-256.

Nunes, B. et al. (2010). Propostas de atividades experimentais elaboradas por futuros professores de Química para alunos com deficiência visual. In Anais XV Encontro Nacional de Ensino de Química. SBQ. [GS Search]

Oliveira, L., \& Bernardon, R. (2008). Instrumento para avaliação de diretrizes estratégicas de sucessão empresarial. In: Revista Gestão e Planejamento, Salvador, 9(2), 141-158. [GS Search] 
Otsuka, J. et al. (2015). Livre Saber (LiSa): Um Repositório de Recursos Educacionais Abertos de Cursos a Distância. In: Revista Brasileira de Informática na Educação, 23(1). DOI: 10.5753/rbie.2015.23.01.1 [GS Search]

Preto, V. (2009). Adaptação de livros de literatura infantil para alunos com deficiência visual [Dissertação de mestrado, Universidade Júlio de Mesquita Filho - UNESP].

Rocha, J., \& Duarte, A. (2012) Diretrizes de acessibilidade web: um estudo comparativo entre as WCAG 2.0 e o e-MAG 3.0. In: Revista Inclusão Social. Brasília, 5(2), 73-86. [GS Search]

Rosa, J., \& Veras, M. (2013). Avaliação heurística de usabilidade em jornais online: estudo de caso em dois sites. In: Revista Perspectivas em Ciência da Informação, 18(1), 138-157. DOI: 10.1590/S1413-99362013000100010 [GS Search]

Santos. A. (2013). Experiências brasileiras com repositórios de conteúdo digital aberto e REA. In Santos, A., Recursos Educacionais Abertos no Brasil: O estado da arte, desafios e perspectivas para o desenvolvimento e inovação (pp. 43-74). UNESCO.

Silveira, M. et al. (2012). Diretrizes para a Avaliação da Usabilidade de Objetos de Aprendizagem. In Anais $23^{\circ}$ Simpósio Brasileiro de Informática na Educação. CBIE. [GS Search]

Silveira, D., \& Córdova, F. (2009). A pesquisa científica. In Silveira, D. e Gerhardt, T. (Orgs.), Métodos de pesquisa (pp. 31-42). Editora da UFRGS.

UNESCO. (2019). Draft Recommendation on Open Educational Resources. In: General Conference $40^{\text {Th }}$ Session. https://unesdoc.unesco.org/ark:/48223/pf0000370936

UNESCO. (2002). Forum on the Impact of Open Courseware for Higher Education in Developing Countries - Final Report. UNESCO https://unesdoc.unesco.org/ark:/48223/pf0000128515

Veraszto, E., \& Vicente, N. (2017). Desenvolvimento de atividades de ensino de citologia para alunos com deficiência visuais: ações de educação inclusiva a partir da Teoria dos Contextos Comunicacionais. In: Revista de Estudos Aplicados em Educação, 2(4), 33-48. DOI: 10.13037/rea-e.vol2n4.4983 [GS Search]

WCAG - WEB CONTENT ACCESSIBILITY GUIDELINES. (2018). Diretrizes de acessibilidade de conteúdo da Web - WCAG 2.1. W3C Recommendation. https://www.w3.org/TR/WCAG21/\#text-alternatives 